\title{
KHAT DISTORTS THE PREFRONTAL CORTEX HISTOLOGY AND FUNCTION OF ADULT WISTAR RATS
}

\author{
Echoru Isaac $^{1 *}$, Bukenya E.M Edmund ${ }^{1}$, Masilili Godfrey ${ }^{1,2}$, Owembabazi Elna ${ }^{1}$, Lemuel Ann Monima ${ }^{1}$, \\ Ahimbisibwe James ${ }^{1}$ \\ ${ }^{1}$ Department of Anatomy, Faculty of Biomedical Sciences, Kampala International University western campus, Bushenyi, Uganda \\ ${ }^{2}$ Department of Human Anatomy, School of Health Science, Makerere University, Kampala, Uganda \\ *Correspondence to Isaac Echoru ${ }^{1}$ Department of Anatomy, Faculty of Biomedical Sciences, Kampala International University western \\ campus, Bushenyi, Uganda. Email echoruisaac@gmail.com
}

\begin{abstract}
Khat is a psychoactive herbal drug of pronounced ethno-pharmacological significance often abused due to its unregulated use. It affects many brain centers including the prefrontal cortex which is the anterior most part of the frontal lobe. The prefrontal cortex modulates working memory, planning complex cognitive behaviors however; it is linked to many psychological disorders such as depression, schizophrenia and memory loss. We studied the effects exerted by khat on the PFC cytoarchitecture and functions since this part of the brain is highly interconnected with various cortical regions. This was an experimental study of 6 weeks. A total of 24 male adult wistar rats of $130 \mathrm{~g}-155 \mathrm{~g}$ were divided into four groups of 6 animals that received respective khat doses of $2000 \mathrm{mg} / \mathrm{kg}, 1000 \mathrm{mg} / \mathrm{kg}, 500 \mathrm{mg} / \mathrm{kg}$ and $10 \mathrm{ml} / \mathrm{kg}$ of distilled water for the controls. Brain to body weight ratio was determined at week 6 using an analytical balance (Fisher Science Education ${ }^{\mathrm{TM}}$, RS232C; USA). Histology of the brain was determined using $\mathrm{H}$ and $\mathrm{E}$ and Kulvers staining technique. Khat exhibited features of prefrontal cortex disorientation such as necrosis, vacuolations, chromatolysis, demyelination, cortical degeneration and hemorrhage in a dose dependent manner. Selective attention and working memory were impaired well as brain to body weight ratio was reduced significantly $(P \leq 0.05)$. Repeated exposure to khat distorts the prefrontal cortex cytoarchitecture and impairs selective attention and working memory accuracy due to ischemia and cell exhaustion by khat toxicity.
\end{abstract}

Keywords: Khat, prefrontal cortex histology, working memory, selective attention

\section{INTRODUCTION}

The main psycho-stimulant in khat is cathinone often found in the fresh young leaves and it is released $15-45$ minutes during chewing. It acts by inducing release of dopamine a neurotransmitter in the brain (Ketema et al., 2015). Khat users have heavily been burdened by traumatic events while others experience khat-related psychotic symptoms (Bhui and Warfa, 2010). Due to its effects, khat has been regarded as a psychostimulant that is likely to alter the structure of neurons in the brain cortical areas (Blanpied and Ehlers, 2004). areas likely to be affected among drug abusers. It is associated with several psychological illnesses such as depression, schizophrenia, obsessive-compulsive disorder, post-traumatic stress disorder (Gregoriou et al., 2014). Its functions include; memory, planning complex cognitive behaviour, decision making, personality expression, verbal reasoning, problem solving, multi-tasking, monitoring of actions (events) and attention collectively termed as executive functions (Yuan and Raz, 2014).

The PFC projection into the limbic system

The prefrontal cortex (PFC) is one of the cortical

Submitted $10^{\text {th }}$ August 2017, Corrected $26^{\text {th }}$ January 2018. Published online $28^{\text {th }}$ February 2018. To cite: Echoru I, Bukenya EM, Masilili G, Owembabazi E, Lemuel AM, Ahimbisibwe J. 2018. Commonly Consumed KHAT (Catha Edulis) distorts the Prefrontal Cortex Histology and Function in Adult Wistar Rats. Anatomy Journal of Africa. 7: 1121 - 1132. 
region enables a total control on the implementation of goal-directed behaviors. Through glutaminergic pathways, the PFC sends outputs to the hippocampus and amygdala of the limbic system which later control the activity of the nucleus accumbens (Arco and Mora, 2009). Dopamine and acetylcholine neurons in the brainstem and forebrain areas are also regulated by PFC glutaminergic projections and they appear to be significant in moderating motor and emotional (Floresco, 2013). Consequently, both pathological and physiological changes in the
PFC may impact the activity of these limbic areas and the corresponding final behaviours (Arco and Mora, 2009). Alteration in the PFClimbic system interactions may bring about psychiatric disorders due to environmental dependent neuroplasticity (Macdonald et al., 2016). Due to a high burden of psychological illnesses, community-based interventions instantly need to be developed by help of scientific research in exposing the effects. This study sought to address the gap as to whether khat could be responsible for psychological or cognitive impairments amongst its users.

\section{MATERIALS AND METHODS}

The study was a randomized experimental design that was carried out for a maximum duration of 6 weeks. About 24 adult male Wistar rats that weighed $130 \mathrm{~g}-155 \mathrm{~g}$ were used in the study. Prior to the start of the experiment, the animals were divided into four groups with six animals each. Respective doses of $500 \mathrm{mg} / \mathrm{kg}, 1000 \mathrm{mg} / \mathrm{kg}, 2000 \mathrm{mg} / \mathrm{kg}$ of $\mathrm{khat}$ extract and the control group were administered to the animals. The control group was given $10 \mathrm{ml} / \mathrm{kg}$ of distilled water. All animals were maintained in their wooden cages with iron netting. It was ensured that all animals received 12-hour day light and 12-hour dark cycles at temperatures of $24 \pm 2{ }^{\circ} \mathrm{C}$. The animals were allowed to acclimatize to their new environment for one week prior to start of the experiment while being allowed free access to distilled water and food ad libitum (Adelaja et al., 2006). Our study was conducted in accordance to the National Institute of Health Guide for the Care and Use of Laboratory Animals ( $8^{\text {th }}$ edition) whereby all animals were provided adequate water, food, ventilation, space and no unnecessary stress was imposed to the animals.

\section{Plant collection and extraction}

About $8 \mathrm{~kg}$ of fresh khat leaves were purchased from Mirokola village, Ishaka sub-county in Bushenyi district. The plant samples were taken to Mbarara University of science and technology, faculty of science for botanical identification (ID NO: \#001Catha edulis).

The method of extraction was described according to Alsalahi et al., (2012) and Alele et al., (2013) with some modifications. Fresh leaves were washed in distilled water to remove dust and debris. About $5 \mathrm{~kg}$ of fresh leaves were air-dried in a dark place for two weeks. The dried leaves were ground to powder using a motor and pestle, then weighed and stored in a clean sterile glass container. Extraction was done using ethanol $80 \%$ in a Buchi-type soxhlet apparatus i.e. $5 \mathrm{ml}$ of ethanol per $1 \mathrm{~g}$ of khat powder. Ethanol as opposed to water was used as extraction solvent because it was known to produce considerable levels of cathinone and cathine from khat (Alele, 2016). First phase extraction was done by spinning the mixture for 24 hours using a magnetic stirrer at room temperature $24 \pm 3^{\circ} \mathrm{C}$. The mixture was then filtered using Whitman filter paper $(11 \mu \mathrm{m}$ pore size). The filtrate was concentrated to near dryness using a Buchi-type soxhlet apparatus at $120 \mathrm{rpm}$ and temperature of $50^{\circ} \mathrm{C}$ for 16 hours. After concentration, the resulting yield was weighed. A standard concentration of $200 \mathrm{mg} / \mathrm{ml}$ was prepared by dissolving $5 \mathrm{~g}$ of the concentrate in $10 \mathrm{ml}$ of distilled water. This mixture was spun for 15 minutes using a magnetic stirrer at room temperature $24 \pm 2^{\circ} \mathrm{C}$ then stored in a refrigerator at $6^{\circ} \mathrm{C}$ ready for administration to the animals as per their body weight. 
Khat extract was administered orally according to body weight using an oral gastric tube. Administration of the extract was given between 3 to $5 \mathrm{pm}$ daily. The doses were given as follows; $500 \mathrm{mg} / \mathrm{kg}, 1000 \mathrm{mg} / \mathrm{kg}, 2000$ $\mathrm{mg} / \mathrm{kg}$ and control group received $10 \mathrm{ml} / \mathrm{kg}$ of distilled water. The above doses were selected according to previous studies as equivalent doses to the amount of fresh khat leaves consumed by khat users (Alsalahi et al., 2012).

The body weight of the animals was measured on the first day before treatment then once every week during the period of extract administration (treatment). After dissection, the whole brain was removed and weighed using an analytical balance (Fisher Science Education $^{\mathrm{TM}}$, RS232C; USA). The relative brain weight was determined by dividing brain by body weight and expressed as a percentage ratio (Adelaja et al., 2006).

\section{Determination of working memory response accuracy}

This experiment was done in the $6^{\text {th }}$ week for five days before animal sacrifice. The method used was described according to Chudasama, (2011). In this study, a spatial delayed response task was used which involved testing one animal at a time. The animal was seated in its cage facing two identical food containers positioned at a distance from each other. The animal was allowed to observe the experimenter place a food morsel in one of two food containers. Each of the food containers was covered with two identical objects. An opaque shutter was lowered between the animal and the objects. After a delay of ten seconds, the shutter was raised and the animal was tasked to retrieve the food morsel by displacing the object under which the food morsel was placed. This task was carried out in the morning just before adding food to the animals. The task was performed in the $6^{\text {th }}$ week every morning for five days; the time taken to reveal the food morsel was recorded and classified as accurate score if less than 10 seconds. A total of 20 trials were done per rat and accurate scores were expressed as a percentage of all the total trials.

\section{Determination of selective attention response accuracy}

This experiment was also done in the $6^{\text {th }}$ week for five days before animal sacrifice The method used was described by Chudasama, (2011). The technique used was called a 5choice serial reaction time task (5-CSRRT) and it was designed by Carli et al. (1983) to measure attentive effects of psychoactive drugs as part of executive function of the PFC. A rat was placed behind an arc of nine holes at the front of the box and was required to face five holes at the back of the box. The rat had to observe a brief occurrence of light for 2 seconds projected in one of the five holes at the back of the box. A positive response was detected by a nose poke in one of the five holes. For any correct responses, a reward of food pellets was placed at the back of the chamber. The following errors were taken into consideration; response in a hole where light had not been presented (error of commission), failing to respond to light within the prescribed time limit (error of omission) and response prior to the onset of light stimulus. After observing any errors, the rat was allowed to go into a brief period of darkness and the experiment had to be initiated by a giving food pellets. The task tested ability of each rat to sustain attention divided among a number of locations and 50 trials were made per rat. Measurement of attention accuracy was determined as a proportion of correct detections over total correct detections plus errors of commission excluding errors of omission and expressed as a percentage.

Anesthesia was done by placing the rat in a tight container with cotton wool soaked in diethyl ether. Precaution to avoid any physical injury to the brain was taken by perfusion of the rat with $4 \%$ formaldehyde solution in $0.1 \mathrm{M}$ phosphate buffered saline at $\mathrm{PH}$ of 7.3 before dissection to remove the brain. After anesthesia, the rat was laid in a supine position 
on a dissection board with limbs stretched outwards using pins. A sagittal incision was made through the thoracic cavity and the ribs were reflected and held laterally. A 21-gauge needle attached a plastic tubing was connected to the syringe with the perfusate solution which was then introduced into the left ventricle. A pair of scissors was used to cut through the right atrium to allow blood escape the body during perfusion. The rat was held gravitationally with the head downwards for about 5 minutes until all the fluid that came out of the rat was clear and free of blood. The rat was then placed in a prone position with limbs pinned outwards and incisions were made through the skin and skull in order to expose the brain.

Brains were removed after perfusion and fixed in neutral buffered formalin for 12 hours. After fixation, the brains were dehydrated in ascending grades of alcohol and embedded in molten paraffin wax. Coronal paraffin sections of $3 \mu \mathrm{m}$ and $10 \mu \mathrm{m}$ were cut from one hemisphere and allowed to dry in an oven at $37^{\circ} \mathrm{C}$ overnight. Sections were mounted onto gelatin coated slides then stained with routine hematoxylin and eosin and Kulvers stain respectively.

After staining, slides were examined (with the help of a veterinary pathologist) using a light microscope (Nikon Eclipse, 104c, Japan). Micrographs were captured with a digital camera (Nikon digital sight DS Fi1, Japan) attached to the microscope and run by NISElement F3.00, SP7, Build 547 software. Cells were counted using image J software.

Animal handling, cage hygiene, waste management, anesthesia, incineration of animal remains was according to the guideline for care and use of laboratory animals version 8 . All the animals were provided with adequate distilled water, food, ventilation, space and no unnecessary stress was subjected to any of the animals during the experiment (Ketema et al., 2015).

\section{RESULTS}

There was a general body weight increase in the first 3 weeks followed by gradual decline in the body weight from week 4 to 6 as shown in FIGURE 1 below. At week 6 , there was statistical difference in weight among $1000 \mathrm{mg} / \mathrm{kg}$ and $2000 \mathrm{mg} / \mathrm{kg}$ groups $(P<0.05)$, FIGURE 2 below. The graph in FIGURE 3 below

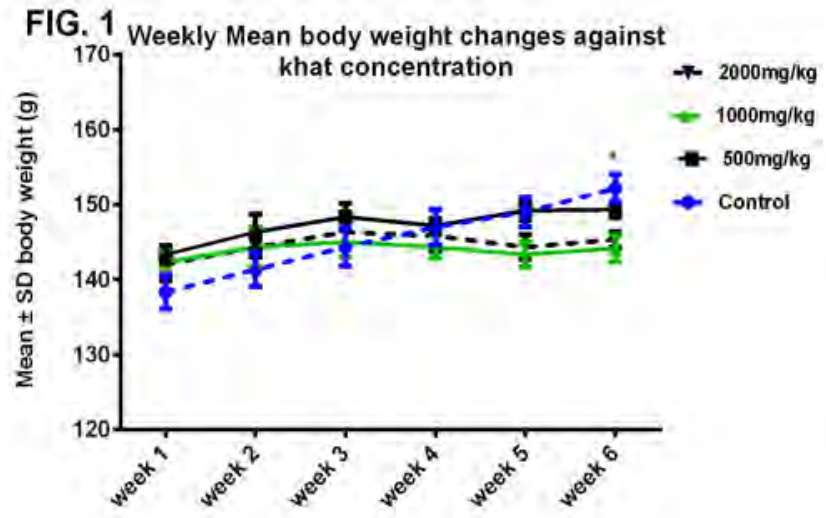

shows that there was a gradual decrease in the brain weight of the rats significant in the $2000 \mathrm{mg} / \mathrm{kg}$ group $(p<0.05)$. FIGURE 4 below shows that there was gradual decrease in brain to body weight ratio with significant difference in the $2000 \mathrm{mg} / \mathrm{kg}$ group as compared to the controls $(P<0.05)$.

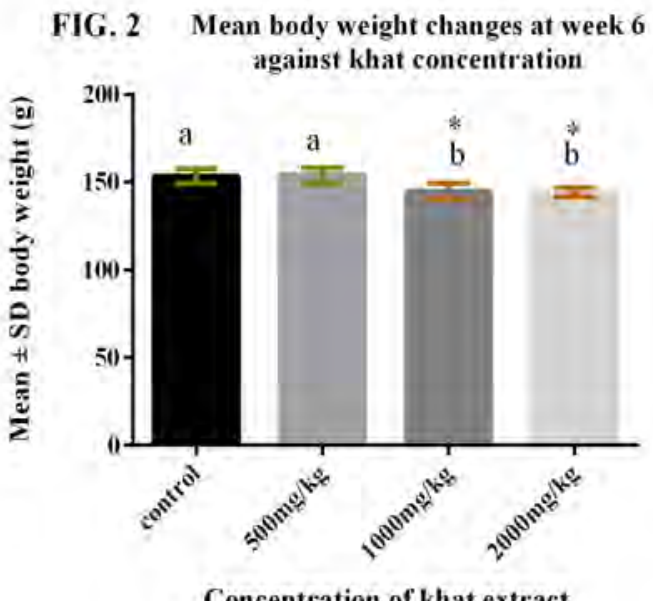

Concentration of khat extract 

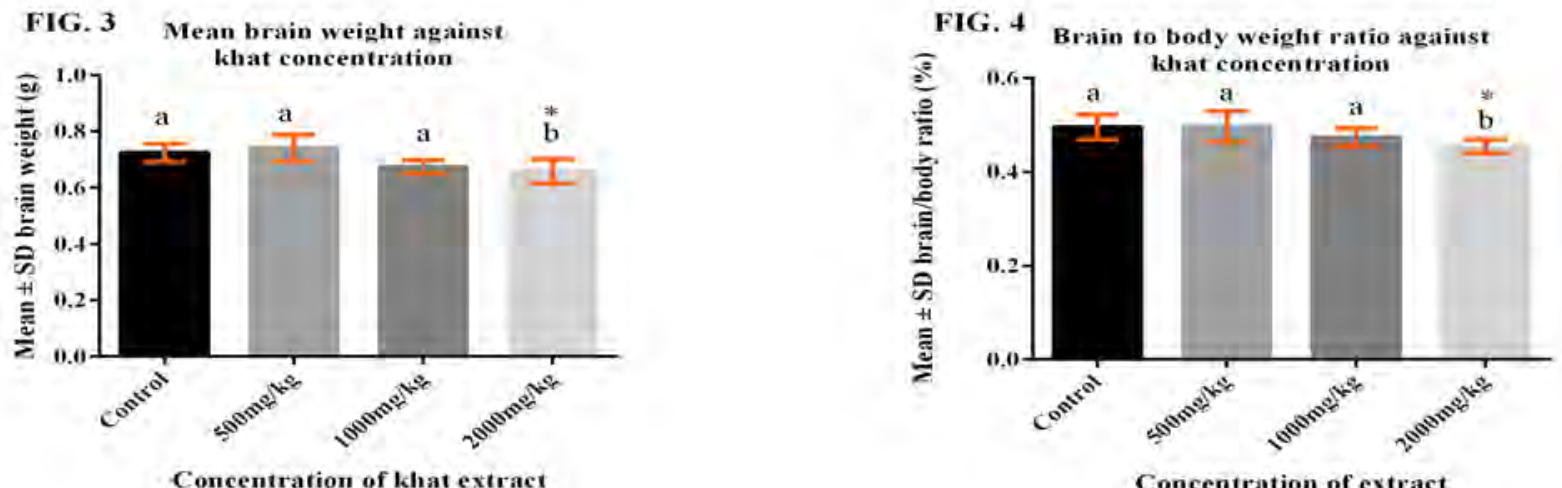

FIGURES 1-4 above show effects of khat on brain and body weight of wistar rats. Statistical analysis (ANOVA) in 1 shows significant weight difference between groups at week six $(P \leq 0.05)$ and 2 shows that the weight difference occurred in the $1000 \mathrm{mg} / \mathrm{kg}$ and $2000 \mathrm{mg} / \mathrm{kg}$ as each was compared to the control group. Brain to body weight ratio in $\mathbf{4}$ was only significantly different in the $2000 \mathrm{mg} / \mathrm{kg}$ group as compared to the controls $(P \leq 0.05)$. All the weights were expressed as percentages of mean brain/body weight with error bars showing standard deviation (SD) in mean weights. Letters ${ }^{\mathrm{a}}$ b represents mean weight difference between groups and * shows the level of significance.

\section{Effects of khat on working memory and selective attention in wistar rats}

From the graph in FIGURE 5 below; there was a decline in working memory response accuracy of the rats and statistical analysis showed significant decrease in all groups as compared

FIG. 5

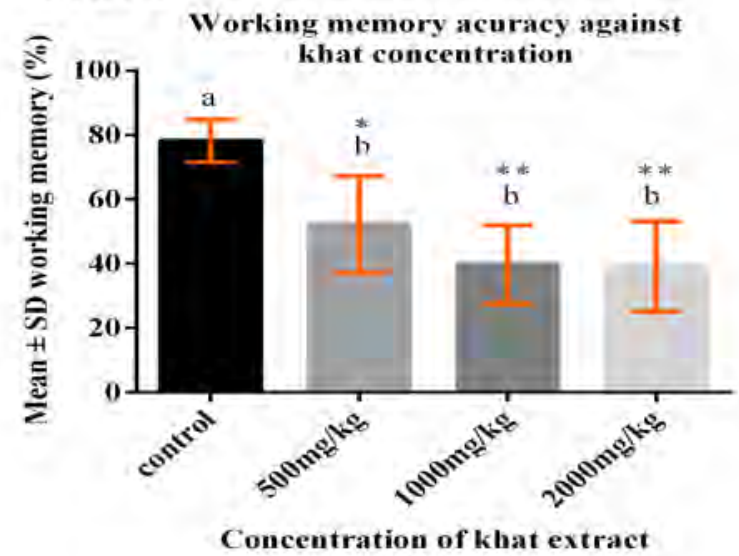

to the controls $(P \leq 0.05)$. The level of significance was greater with increase in the concentration of khat extract. FIGURE 6 below shows that selective attention accuracy gradually decreased with increase in khat dose.

FIG. 6

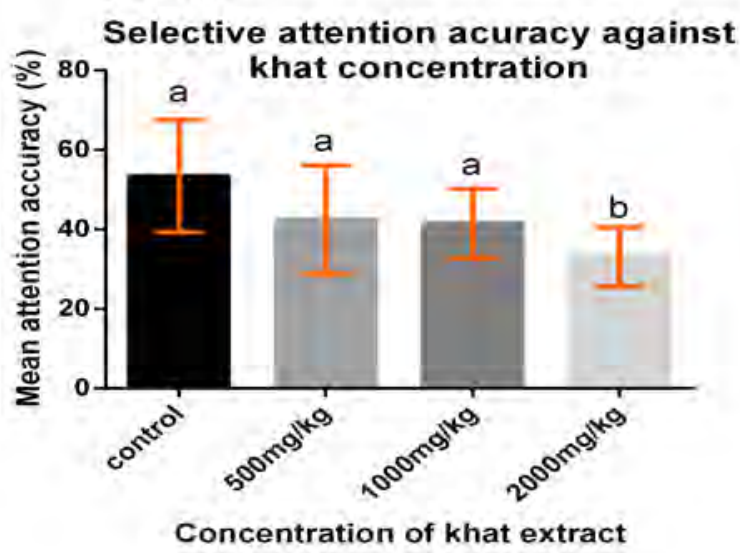

Fig 5 and 6: The effects of khat on working memory and selective attention in the rats are shown. Working memory decreased significantly $(P \leq 0.05)$ as khat concentration was increased. Selective attention showed no significant decrease except in the $2000 \mathrm{mg} / \mathrm{kg}$ group. All test groups were compared with control groups using POST HOC Tukey's comparison test. Letters ${ }^{a}$, b represent difference in accuracy between experimental groups and * shows the level of significance. Significance was tested at $95 \%$ confidence interval when $(P \leq 0.05)$. 

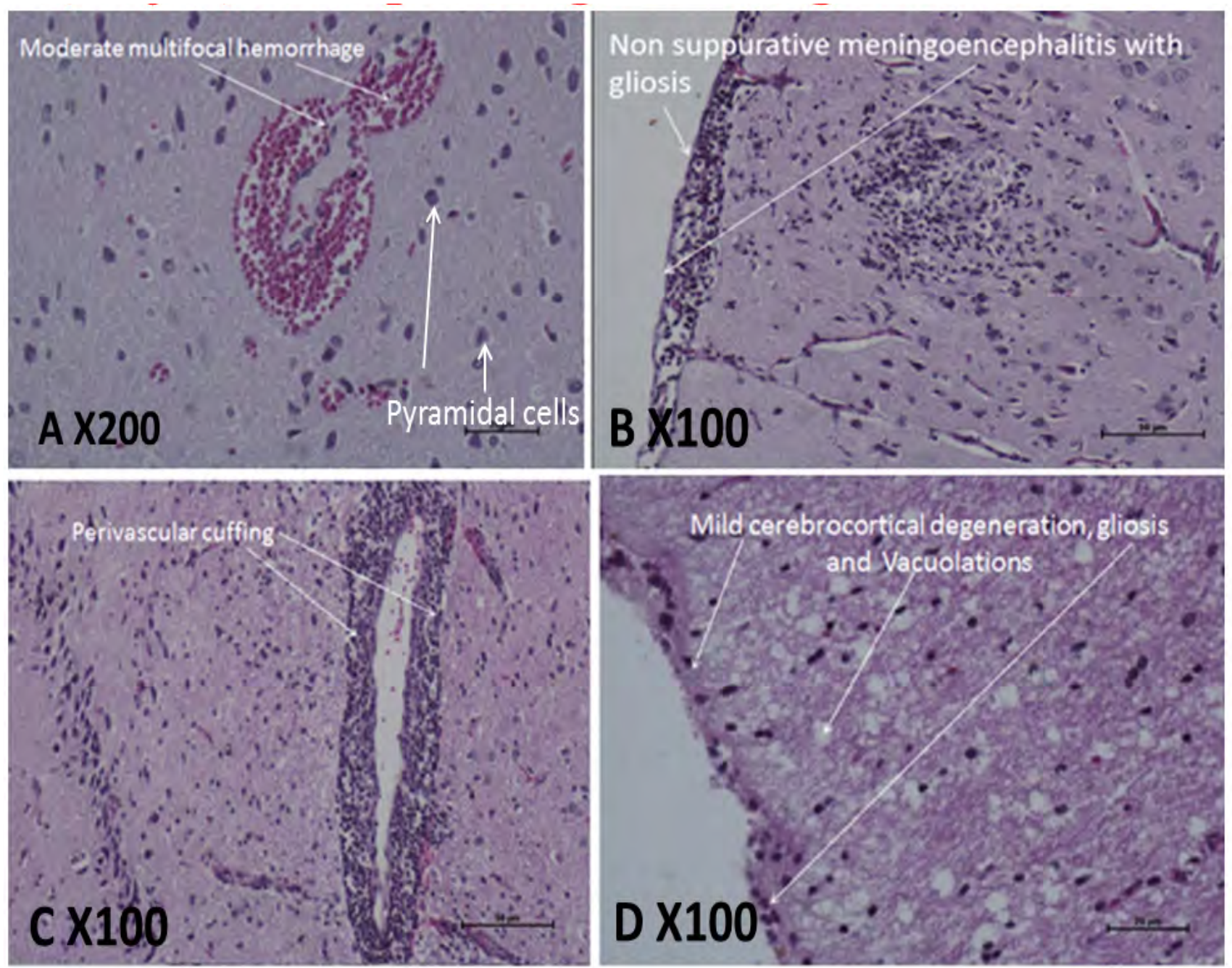

Fig 7: Photomicrographs showing effects of khat on the PFC parenchyma.

The photomicrographs above are from Hematoxylin and Eosin stain showing histopathological findings in the PFC of wistar rats after khat administration. Plate A: Shows moderate multifocal hemorrhage that occurred in all test groups. Plate B: Shows non suppurative meningoencephalitis and gliosis of astrocytes and microglial cells. Plate C: Shows perivascular cuffing. Perivascular cuffing was seen majorly in the $1000 \mathrm{mg} / \mathrm{kg}$ and $2000 \mathrm{mg} / \mathrm{kg}$ test groups. Plate D: Shows cerebrocortical degeneration occurred in both $1000 \mathrm{mg} / \mathrm{kg}$ and $2000 \mathrm{mg} / \mathrm{kg}$ dose groups while vacuolations were seen in all test groups however; they were severe in a dose dependent manner.

FIG. 8

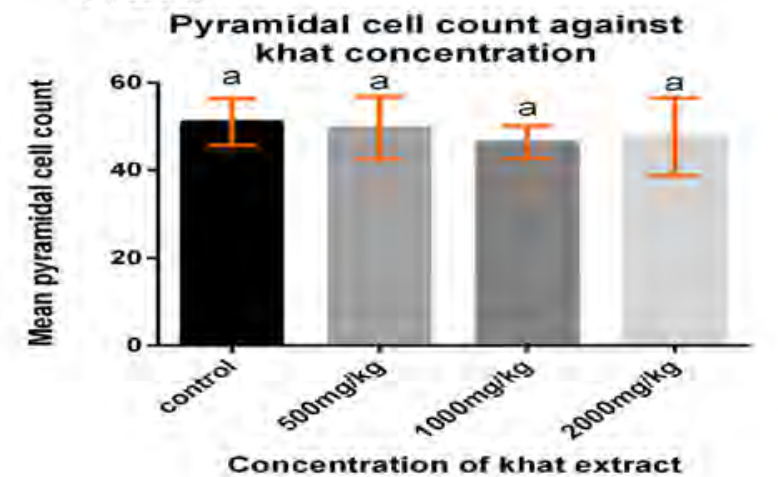

FIG, 9

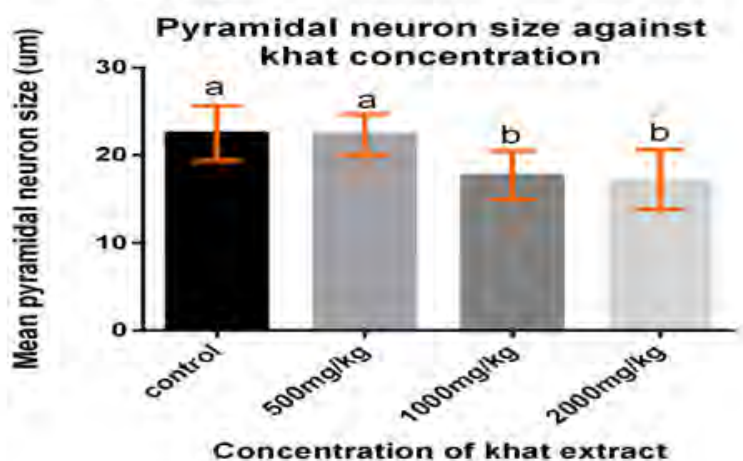


Fig 8 and 9: Effects of khat on size and number of pyramidal cells. Pyramidal cell count showed no significant change $(P \geq 0.05)$ while pyramidal cell size significantly decreased $(P \leq 0.05)$ among the $1000 \mathrm{mg} / \mathrm{kg}$ and $2000 \mathrm{mg} / \mathrm{kg}$ groups as all as compared to the controls and. The error bars show standard deviation in the means. Letters ${ }^{a}, b$ represent difference in cell count and cell size between experimental groups.
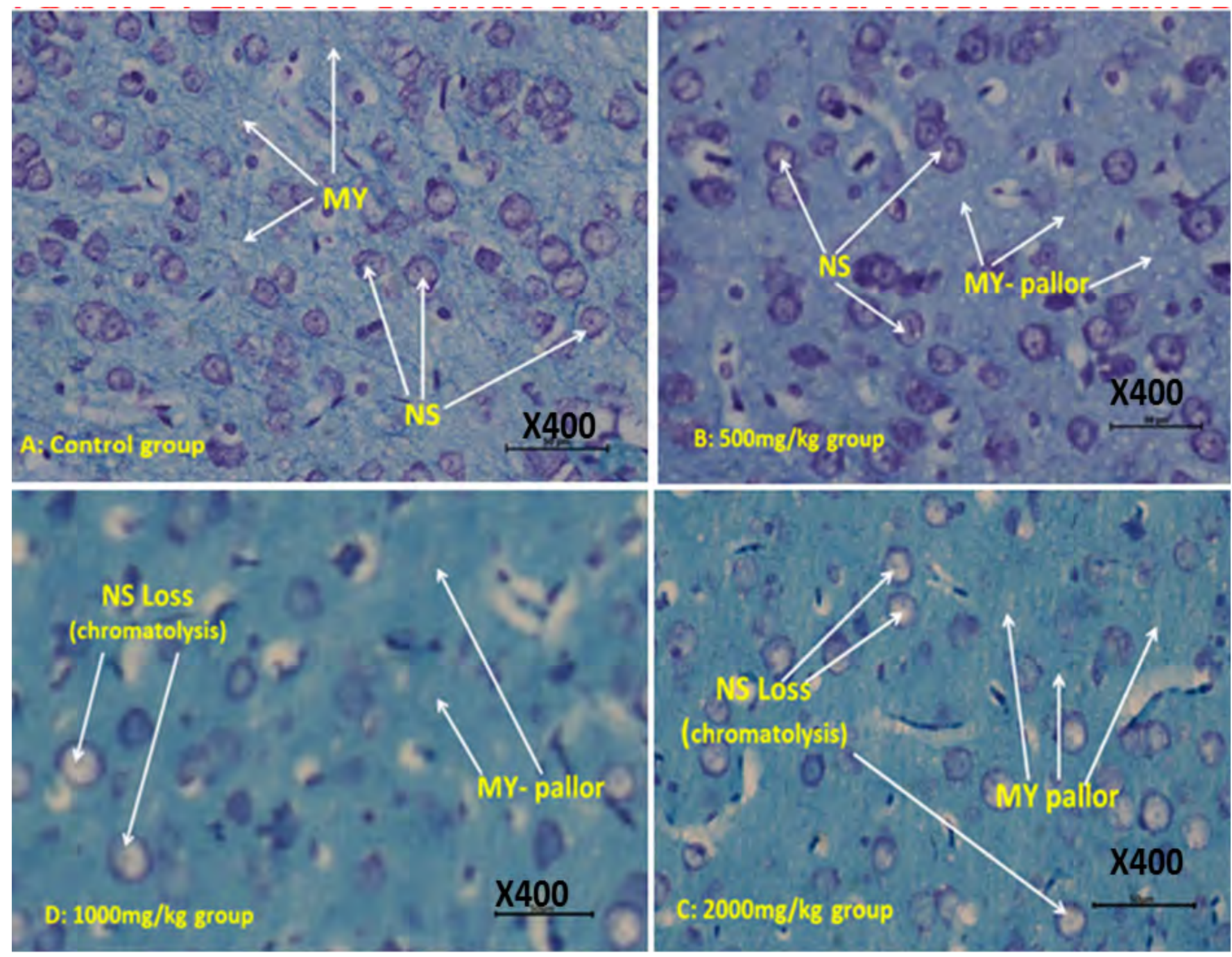

Fig 10: Photomicrograph showing effects of khat on Nissl substance and Myelin sheath in the PFC. KEY: MY- Myelin; NSNissl substance. The photomicrographs (x400) above were obtained from the rat PFC after Kulvers staining technique. Plate A: shows cell bodies with their small compact nuclei and myelin at the background with a blue stain; Plate B: shows cell bodies with severe chromatolysis (loss of Nissl substances) and myelin pallor seen in $1000 \mathrm{mg} / \mathrm{kg}$ and $2000 \mathrm{mg} / \mathrm{kg}$ groups.. Plate C: Shows myelin pallor and severe chromatolysis.

\section{DISCUSSION}

There was a significant decrease in brain to body weight ratio of rats in the $2000 \mathrm{mg} / \mathrm{kg}$ group. Reduction in brain to body has a lot to predict about cognition and intellectual abilities in animals (Lemieux et al., 2015). Andrian and Bingshuo in 2010 reported that khat reduced body weight of male rats at high doses and this was attributed to anorexigenic effect and harsh effects of khat on the intestinal mucosa hence affecting food absorption. In addition, it has been shown that khat toxicity can cause hepatic encephalopathy which disrupts central nervous 
system functioning by altering the dendritic morphology of cortical and hippocampal pyramidal neurons leading to motor and intellectual impairments (Radhu et al., 2015). Previous studies have correlated bodyweight loss to a drop-in leptin level and that cathinone in khat influencing release of leptin hormone. This hormone has its receptor sites in the hypothalamus where it inhibits appetite centers (Alele et al., 2013). From this study, it is believed that khat suppressed appetite by increasing the synaptic availabilities of norepinephrine and dopamine in hypothalamus, and consequently activating the norepinephrine and dopamine dependent mechanisms that lessen the central nervous system regulation of food intake. Neuronal damage in the PFC could have damaged synaptic interconnections with the hypothalamus. Structural damage progressed to numerous behavioral, neurophysiological and molecular mechanisms that are known to regulate anorexic mechanism of the hypothalamus hence low food intake. It is not easy to establish the level of intelligence in animals however; the larger the brain to body weight ratio, the more the brain mass available for more complex cognitive tasks and vice versa.

This study also showed that khat caused impairment in working memory of wistar rats in a dose dependent manner. Previous findings have shown that khat impaired learning and memory in mice using a Morris water maze technique (Samuel K and Albert W, 2008). Damage to PFC neurons and their receptor sites inhibits release and uptake of neurotransmitters hence no inter-neuronal communication that could have resulted in impaired working memory. Previous studies have also shown that lesions in the PFC of humans and non-human primates have impaired working memory function (Gregoriou et al., 2014); therefore any factors that may alter the PFC parenchyma may impair working memory. Additional studies have shown that psychoactive drugs increase concentration of neurotransmitters such as dopamine, serotonin and noradrenaline in specific regions of the brain which results into an influx of neurotransmitter at the synaptic cleft (Fernandez-Espejo and RodriguezEspinosa, 2011). Therefore, excessive stimulation of doperminergic neurons by cathinone could have led to damage and inhibition of dopamine uptake at the receptors.

Khat also impaired selective attention accuracy in a dose dependent manner. Impairment in this task revealed likelihood of lesions in the PFC. Similar studies in humans have shown that long time chewing of khat results in cognitive function loss (Gregoriou et al., 2014. This has been witnessed by an increase in the number of road traffic accidents with in khat chewing communities (Colzato et al., 2011). Our study also supports arguments that khat chewing is associated with socioeconomic and familial problems. It has been noted that most men that chew khat often secure their daily share of khat at the expense of important family needs. Family life is therefore affected because of neglect, dissipation of family income. This study has attributed reduction in attention accuracy to hemorrhage with in the PFC parenchyma that impaired nutrient delivery to neurons hence causing them to shrink and degenerate. Injury to neurons alters their morphology and ability to signal through cellular interconnections. Because neurotransmitters have their receptors on neurons, any change in neuromorphology alters receptor sites hence limits neurotransmitter uptake.

Khat also caused histopathological changes in the PFC of wistar rats that included; multifocal vacuolations, gliosis, focal necrosis and hemorrhage within the PFC of wistar rats. Comparably studies have shown that frequent use of psychostimulants may bring about morphological changes in the dendrites and increase in the number of dendritic spines hence changing cell to cell coupling and development of new gap junctions. This reduces on cell to cell communication leading to impaired movement of nutrients across leading to cell death (Fernandez-Espejo and RodriguezEspinosa, 2011). Another study has shown that 
psychostimulants induce neuronal injury and decrease dendritic branching leading to loss of synapses (Muche and Abdelwuhab, 2007). This study also reports a decrease in the size and number of pyramidal neurons in the PFC. This reduction was attributed to neuroplastic changes due to constant exposure to khat. An attempt to respond to nerve injury results in to extreme neuronal growth that leads to over release of neurotransmitters. Pyramidal neurons of the PFC have serotonergic and dopaminergic receptors however, psychiatric drugs alter the structure of neurons and their receptor which are located on the dendrites hence altering their functions (Robbins, 2002); (Oda and Tanaka, 2014). Khat has also been shown to cause disruption of neuronal integrity and purkinje cells in the cerebellum of rats (Muche and Abdelwuhab, 2007).

Our findings of cerebral hemorrhage were similar to a study by Mujlli et al., (2005) that showed that khat users developed an acute cerebral infarction and increase in high blood pressure due to vasoconstriction potentials of cathinone. Cerebral haemorrhage cuts off oxygen and blood supply to the tissues leading to necrosis and tissue degeneration. During cerebral ischemia, there is a rapid increase of intracellular calcium which initiates changes in

\section{Competing interest}

The authors declare that there exist no competing interests.

\section{REFERENCES}

1. Abdelwahab SI, Alsanosy RM, Rahim BEA, Mohan S, Taha S, Elhassan MM, El-setouhy M. 2015. Khat (Catha edulis Forsk) Dependence Potential and Pattern of Use in Saudi Arabia. BioMed Res Intern, 148(2), 383-497

2. Adelaja AA, Olatunde O, Ejiwunmi AB. 2006. The Neurotoxic Effects of Artemether on the Cytoarchitecture of the Trapezoid Nuclei of Adult Male Wistar Rats (Rattus novegicus). Int J Morphol, 24(4), 535-540.

3. Alele PE. (2016). Projection neurons in the cortex and hippocampus: differential effects of chronic khat and ethanol exposure in adult male rats Projection neurons in the cortex and hippocampus : differential effects of chronic khat and ethanol exposure in adult male rats. J Exp Pharmacol, 8, 43-52.

4. Alele PE., Ajayi AM, Imanirampa L. 2013. Chronic khat (Catha edulis) and alcohol marginally alter complete blood counts, clinical chemistry, and testosterone in male rats. J Exp Pharmacol, 5, 33-44.

5. Alsalahi A, Abdulla MA, Al-Mamary M, Noordin MI, Abdelwahab SI, Alabsi AM, Alshawsh MA. 2012. Toxicological features of Catha edulis (Khat) on livers and kidneys of male and female 
Sprague-Dawley rats: A subchronic study. Evidence-Based Comp Alt Med,126, 231-245

6. Arco A, Mora F. 2009. Neurotransmitters and prefrontal cortex-limbic system interactions: Implications for plasticity and psychiatric disorders. J Neu Trans, 116(8), 941-952.

7. Barbas H. 2010. Prefrontal Cortex: Structure and Anatomy. Ency Neurosci, 909-918.

8. Bhui K, Warfa N. 2010. Trauma, khat and common psychotic symptoms: A quantitative study. J Ethnopharmacol, 131(2), 459-463.

9. Blanpied TA, Ehlers, MD. 2004. Microanatomy of dendritic spines: Emerging principles of synaptic pathology in psychiatric and neurological disease. Biol Psychiatry, 55(12), 1121-1127.

10. Buschman, TJ, Buschman TJ, Miller EK. 2007. Top-Down Versus Bottom-Up Control of Attention in the Prefrontal and Posterior Parietal Cortices. Pharmacol Biochem Behav, 1860, 1013.

11. Butenko O, Dzamba D, Benesova J, Honsa P, Benfenati V, Rusnakova V, Anderova M. 2012. The Increased Activity of TRPV4 Channel in the Astrocytes of the Adult Rat Hippocampus after Cerebral Hypoxia / Ischemia. Am J Psychiatry, 141: 1421-1432

12. Chudasama Y. 2011. Animal Models of Prefrontal-Executive Function. Behav Neurosci, 125(3).

13. Dziewulska D, Gogol A, Gogol P, Rafalowska J. 2013. Enlargement of the Nissl substance as a manifestation of early damage to spinal cord motoneurons in amyotrophic lateral sclerosis. Clin Neuropath, 32(6), 480-5.

14. Fernandez-Espejo E, Rodriguez-Espinosa N. 2011. Psychostimulant drugs and neuroplasticity. Biochem Pharmacol, 12(2): 188-195.

15. Floresco SB. 2013. Prefrontal dopamine and behavioral flexibility: Shifting from an "inverted-U" toward a family of functions. Front Neurosci, 24:158-102.

16. Gregoriou GG, Rossi AF, Ungerleider LG, Desimone R. 2014. Lesions of prefrontal cortex reduce attentional modulation of neuronal responses and synchrony in V4. Nat Neurosci, 17(7), 1003-11.

17. Kandari LS, Yadav HR, Thakur AK, Kandari T. 2014. Chat (Catha edulis): A socio economic crop in Harar Region, Eastern Ethiopia. SpringerPlus, 3:579, 1-9.

18. Katsuki F. 2012. Unique and shared roles of the posterior parietal and dorsolateral prefrontal cortex in cognitive functions. Front Integ Neurosci, 6(5), 1-13.

19. Ketema T, Yohannes M, Alemayehu E, Ambelu A. 2015. Effect of chronic khat (Catha edulis , Forsk) use on outcome of Plasmodium berghei ANKA infection in Swiss albino mice. BMC Infec Dis, 15, 1-11

20. Lemieux AM, Li B, Al'Absi M. 2015. Khat use and appetite: An overview and comparison of amphetamine, khat and cathinone. J Ethnopharmaco

21. Macdonald AN, Goines KB, Novacek DM, Walker EF. 2016. Prefrontal mechanisms of comorbidity from a transdiagnostic and ontogenic perspective. Dev Psychopath, 28(4pt1), 1147-1175

22. Muche A, Abdelwuhab M. 2007. Does intake of Ethanol and Khat (Catha Edulis Forsk) Affect The Total Number Of Purkinje Neurons In Early Postnatal Rats? Pharmaco, 114, 102-114.

23. Mujlli HM, Bo X, Zhang L. 2005. The effect of Khat (Catha edulis) on acute cerebral infarction. Neurosci, 10(3), 219-222

24. Oda A, Tanaka H. 2014. Activities of nicotinic acetylcholine receptors modulate neurotransmission and synaptic architecture. Neural Regeneration Research.

25. Radhu N, Dominguez LG, Farzan F, Richter MA, Semeralul MO, Chen R, Daskalakis ZJ. 2015. Evidence for inhibitory deficits in the prefrontal cortex in schizophrenia. Behav Brain Res, 138(2), 483-497

26. Robbins TW. 2002. The 5-choice serial reaction time task: behavioural pharmacology and functional neurochemistry. Psychopharmaco, 163(362), 362-380

27. Samuel KT, Albert WN. 2008. Effects of single daily khat (Catha edulis) extract on spatial learning and memory in CBA mice. Behav Brain Res, 195, 192-197. 
Anatomy Journal of Africa. 2018. Vol 7 (1): 1121 - 1131

28. Yuan P, Raz N. 2014. Prefrontal cortex and executive functions in healthy adults: A metaanalysis of structural neuroimaging studies. Neurosci Biobehav Rev, 18(2), 183-197. 